\title{
Design of the Intelligent Monitoring System for University Dormitory
}

\author{
Zhihong Xiao ${ }^{\mathrm{a}}$, Bowen Ren ${ }^{\mathrm{b}}$
}

School of Electronic Engineering, Xi'an Shiyou University, Xi'an, China

axzhong@xsyu.edu.cn, ${ }^{b} 944394135 @ q q . c o m$

Keywords: Student Research Training Program; students' dormitory; monitoring system; smart home

\begin{abstract}
Student Research Training Program is set up by colleges. This paper introduces the student research training program "design of the intelligent monitoring system for university dormitory". The intelligent monitoring system based on single chip STC12C5A60S2 consists of signal measurement module, the clock module, the keyboard, the display module, audible and visual alarm module, the control module and the communication interface, etc. It can detect and display the information such as actual smokescope, temperature, humidity and the number of students entering into and exiting from the dormitory. When tested data are abnormal, the audible and visual alarm module and the control module are going to work. Through the exercise of the project, students learned how to use their knowledge to solve problems in practice, and their innovative ability and cooperation spirit were also improved.
\end{abstract}

\section{Introduction}

The Student Research Training Program(SRTP). The Program is an important part of the Undergraduate Teaching Quality and Teaching Reform Project set by colleges every year. The main purpose of SRTP is to cultivate the practical ability and innovation consciousness of students. Students are free to organize teams and complete innovative research project design, preparation and implementation of the project study conditions, the researchers report writing, the academic communication and so on autonomously. It can consolidate and deepen students 'understanding of the theoretical knowledge, enable students to master the basic methods of scientific research and cultivate students' innovative consciousness and comprehensive practical ability [1-7].

The Information of the Project "Design of the Intelligent Monitoring System for University Dormitory". The project is supported by student research training program of Xi'an Shiyou University. The safety management of dormitory is very important, and smart home is a promising solution to improve the quality of people's life [8-9]. The project team members looked up plenty of literature, visited a large number of dormitories, and mastered the current dormitory security risks deeply. In order to improve the living safety and comfort of students' dormitory, they put forward the design scheme of the intelligent monitoring system for university dormitory based on the characteristics of the school and smart home concept.

The system can monitor the theft, fire and other unsafe factors inside the students' dormitory. If abnormal circumstances occur, it can be sound and light alarm and notify the dormitory management staff, achieving the safety of student dormitory monitoring. At the same time, through the information detection of air quality, temperature and humidity, the system can control humidifiers and other equipments. It improves the learning and living environment of college students and enhances the quality of students' daily life.

\section{The Composition of the System}

The system consists of microcontroller, signal measurement module, clock module, the keyboard, the display module, audible and visual alarm module, the control module and the communication interface, etc. The hardware block diagram of the system is shown in Figure 1. 


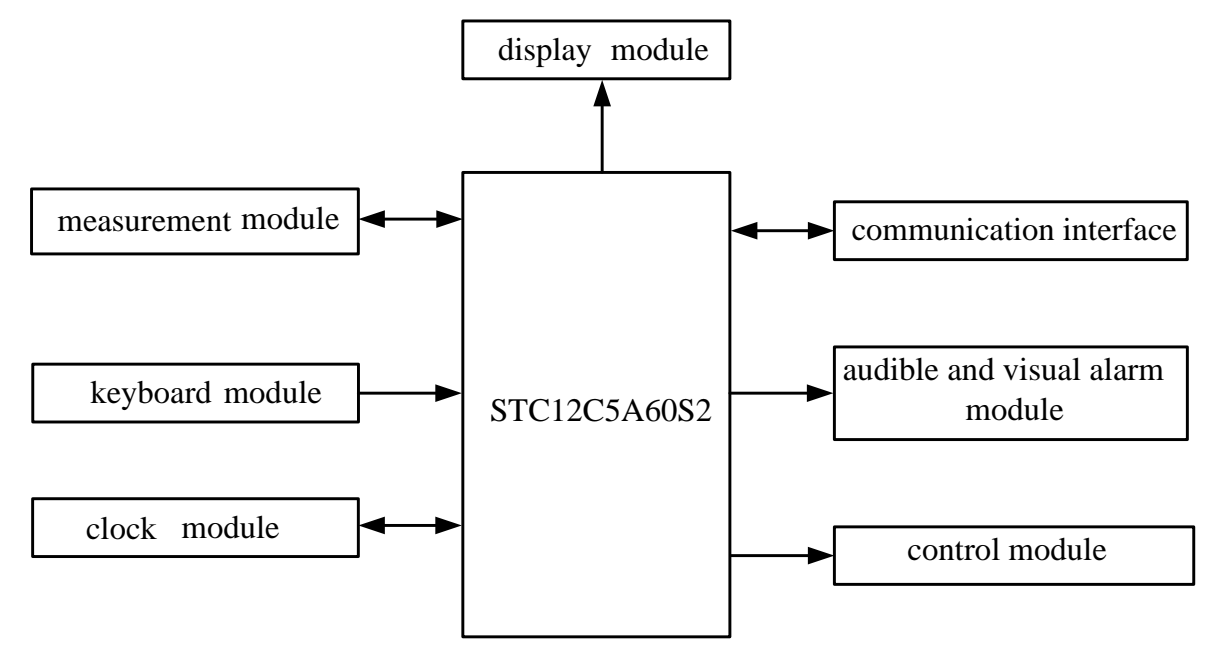

Figure 1. The hardware block diagram of the system

STC12C5A60S2 is a low-power, high-speed CMOS 8-bit microcontroller with 64KB of flash memory. The device is compatible with the industry-standard 80C51 instruction set and pinout, STC12C5A60S2 has 8 A/D and its speed is $8 \sim 12$ times of 89C51 when they have same crystals.

Signal measurement module can detect the information such as actual smokescope, temperature, humidity and the number of students entering into and exiting from the dormitory. It is composed of sensors and their own conditioning circuit. The measurement of smokescope adopts gas censor MQ-2 which has high sensitivity to LPG, Propane and Hydrogen, also can be used to Methane and other combustible steam, smoke. It is with low cost and suitable for different applications. The number of students entering and leaving the dormitory uses photoelectric switches. The temperature and humidity measurement circuit adopts censor SHT15, which enjoys a high level of linearity and the accuracy won't change with the length of wire. Its measuring resolution is 14 bit (temperature) and 12 bit (humidity). Smoke concentration measurement circuit is shown in Figure 2.

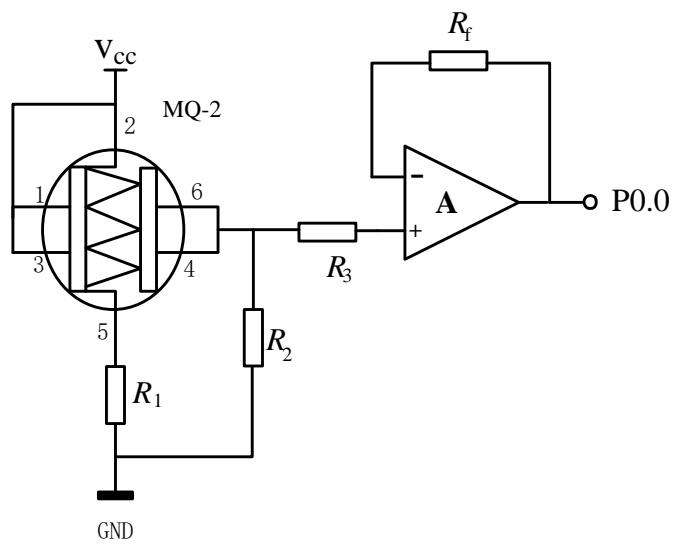

Figure 2. One of the keyboard circuit

Keyboard circuit contains $4 \times 4$ keyboard which can be able to query information, enter the password and password authentication, achieve all kinds of parameter setting online such as the upper and lower limit of alarm of smokescope, temperature and humidity, etc.

Audible and visual alarm module is composed of LED lights and buzzers. It is mainly used for dormitory of sound and light alarm when abnormal situation such as fire and other quarters happened. The control module is used to control the heater, humidifier and other equipment, etc. For example,

When the measured humidity value exceeds the limit value, the alarm lights , buzzer and the humidifier acts at the same time, until the humidity is within the scope of reach standard. A control and alarm circuit is shown in Figure3.

The display module applies LCD display(LCD 128X64-0402B,LCD1602), which is used to display the time, temperature, humidity, smoke concentration, air quality, dormitory class time and other dynamic information. 


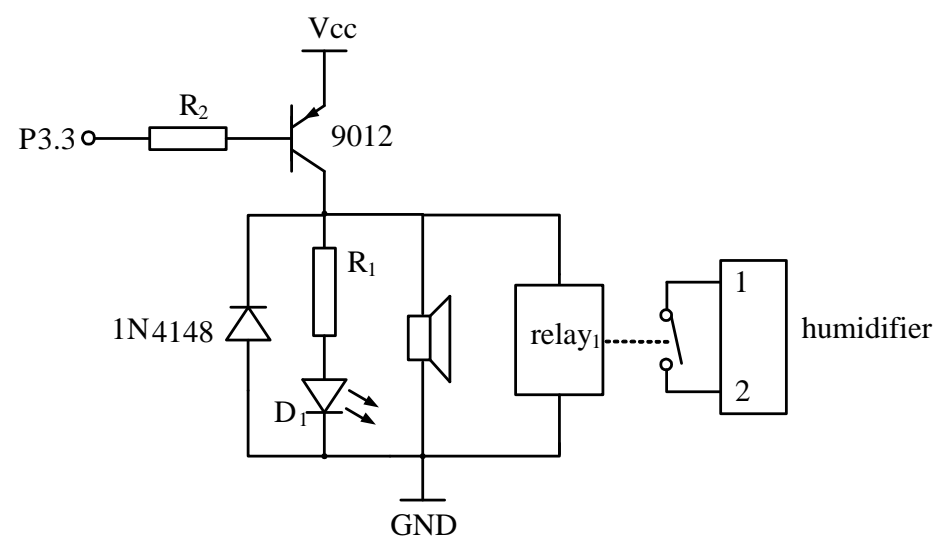

Figure 3. Control circuit of heater

\section{System Software Design}

The system software is designed modularly and consists of main program, smokescope testing program, temperature and humidity testing program, key processing subprogram, interrupt subprogram, the control subprogram, timing program, LCD display program, audible and visual alarm program, and communication program, etc. The main program mainly completes device initialization and calls the appropriate subroutine modules according to the system requirements.

\section{Summary}

According to the program, the students carried out the circuit design, software compilation, drawing circuit PCB board, and completed the installation and debugging of the whole system. The smoke concentration test board is shown in Figure 4. The temperature and humidity monitoring board is shown in Figure 5.

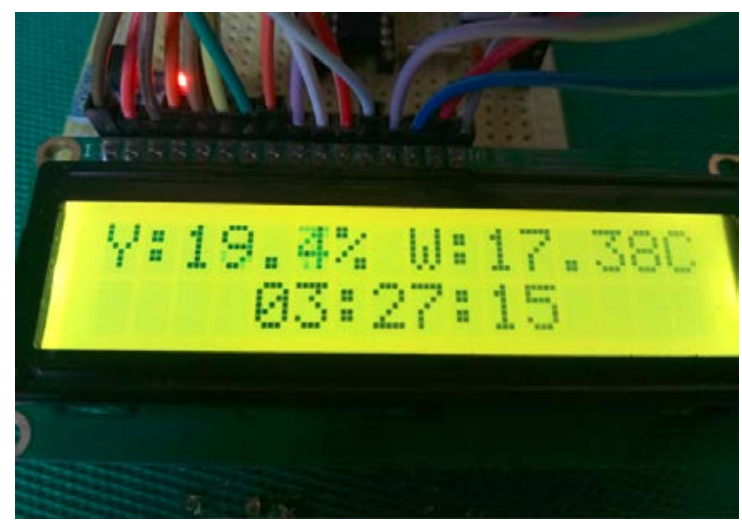

Figure 4. The smoke concentration test board

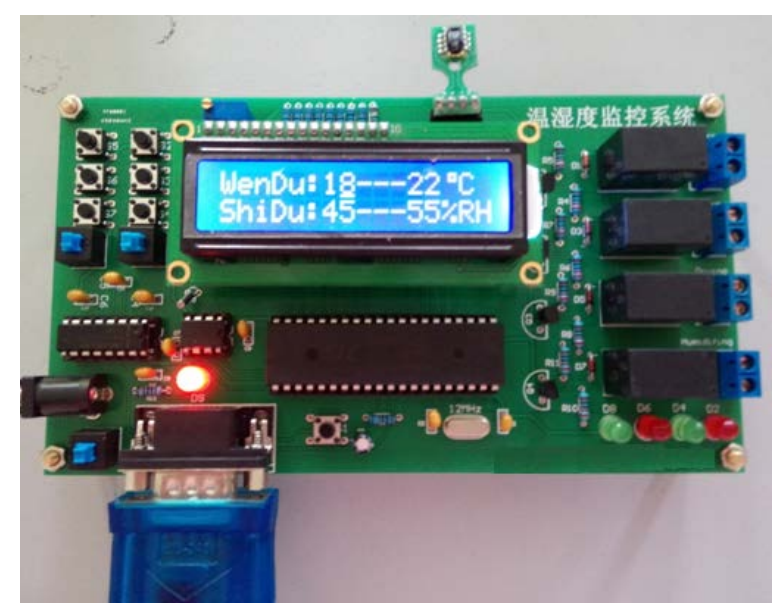

Figure 5. The temperature and humidity monitoring board 
Through the research of " Student Research Training Program " project, students have learned how to use the knowledge they have learned to solve the problems encountered in practice, and their autonomous learning ability, team spirit are greatly improved. In addition, the program improve students' abilities to analyze and solve problems, enhance students' awareness of innovation and solidarity , training students to work independently and rigorously and lay a good foundation for students to work in the future.

\section{Acknowledgements}

The authors would like to express their gratitude to the help of the Student Research Training Program of Xi'an Shiyou University.Thanks are also to all colleagues who previously provide technical support.

\section{References}

[1] Information on http://baike.so.com/doc/8917238-9243913.html.

[2] Raviv, Daniel,Teaching innovative thinking: Future directions, ASEE Annual Conference and Exposition, Conference Proceedings, 2009.

[3] Wang Hailiang, Ren quanchang, Yu Yang, Song Hao, The implementation experience of National college students innovative entrepreneurial training program, China Electric Power Education.25(2013)206-207.

[4] LI Lin, LU Ling-yun, SHEN Ming-xia, HUANG Gui-lin, Research and Practice of Innovative Talents Training Pattern Based on SRTP Plan, Research and Exploration in Laboratory, 02(2009), 8-9.

[5] Kisenwether, Elizabeth C.Matson, Jack V. Launching an undergraduate engineering entrepreneurship program, ASEE Annual Conference Proceedings.2002, pp 8599-8606.

[6] GONG Xin-bao, Cultivating Innovation Practical Abilities through SRTP Project, Journal of Electrical \& Electronic Education, 01(2015), 40-43.

[7] QianXiaoming, Rong Huawei, Qian Jingzhu, Practice and thinking of education of College Atudents Innovative and Entreprepreneurial Training Program based on tutor system, Experimental Technology and Management.7(2014)21-24.

[8] PENG Jun-jie, HE Hui1, ZHU Ping-an, LIU Yan-ping, ZHANG Xue-jun, JIN Yi, Zigbee-based new approach to smart home, Journal of Shanghai University(English Edition) , 01(2010), 33-35.

[9] ZHANG Fan, CHEN Wei-duo, HUA Wei-feng, JING Ke-xing, LUO Hong-xia, Implementation of low-power intelligent dormitory system based on MSP430, Modern Electronics Technique, 06(2014), 41-42.

[10] JIN Yu-yi, REN Yang-hui, LIU Ke-shen, Design of dormitory ARM-based intelligent protection alert measurement and controlling system, Electronic Design Engineering, 03(2014),161-163.

[11] SHI Yu-jun, XIANG Gen-xiang, ZHANG Zhao, An Intelligent Theft and Fire Alarm System Used in the Dormitory, Electrical Automation , 04(2014), 85-86.

[12] ZENG Song-wei, ZHANG Yun, QIU Wei -qiang , Design of Smart Home Control System Based on IOT Modern Electronics Technique , 34,9 (2011), 168-169.

[13] Information on http://www.elecfans.com/soft/165/2013/20130906327522.html 